Indexed by

\title{
Scopus'
}

\section{WALKING PROPELLERS OF TRANSPORTATION VEHICLE FOR DRIVING UNDER STEPPE ROAD-OFF CONDITIONS}

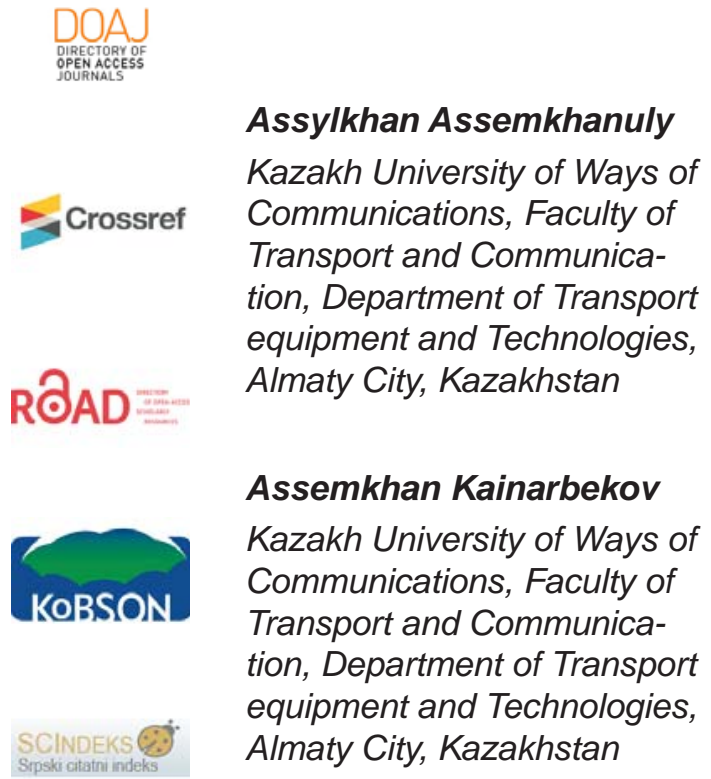

\author{
Zansaya Niyazova \\ Kazakh University of Ways of \\ Communications, Faculty of \\ Transport and Communication, \\ Department of Transport \\ equipment and Technologies, \\ Almaty City, Kazakhstan

\begin{abstract}
Kanagat Bekmambet
Kazakh University of Ways of Communications, Faculty of Transport and Communication, Department of Transport equipment and Technologies, Almaty City, Kazakhstan
\end{abstract}

\begin{abstract}
Abil Muratov
Kazakh University of Ways of Communications, Faculty of Transport and Communication, Department of Transport equipment and Technologies, Almaty City, Kazakhstan
\end{abstract}

Key words: walking propellers, transportation, vehicle, steppe road-off conditions doi:10.5937/jaes18-26598

\section{Cite article:}

Assemkhanuly, A., Niyazova, Z., Muratov, A., Kainarbekov, A., \& Bekmambet, K. [2020].Walking propellers of transportation vehicle for driving under steppe road-off conditions. Journal of Applied Engineering Science, 18(3), 355 - 363. 


\title{
WALKING PROPELLERS OF TRANSPORTATION VEHICLE FOR DRIVING UNDER STEPPE ROAD-OFF CONDITIONS
}

\author{
Assylkhan Assemkhanuly*, Zansaya Niyazova, Abil Muratov, Assemkhan Kainarbekov, \\ Kanagat Bekmambet
}

\section{Kazakh University of Ways of Communications, Faculty of Transport and Communication, Department of Transport equipment and Technologies, Almaty City, Kazakhstan}

Vast steppes of Kazakhstan mainly consist of stubble and sandy loam soils, as well as salt marshes with solid surface. Therefore, it is possible to drive on them on conventional vehicles with pneumatic wheels. Where the land is developed for grain crops, the surface of the soil is soft, and where fodder crop rotations are cultivated, the surface of the soil is as solid as stubble.

Wherever land is used for economic needs, wheeled cars, tractors and agricultural machinery drive there. Unfortunately, they deteriorate a lot.

Service life time of trucks and cars in off-road conditions compared with service lifetime of them in urban environments is reduced by almost four times.

Tractor trucks, tractor cultivators and all types of self-moving wheeled agricultural machinery are annually subjected to seasonal repairs as a result of agricultural harvesting. Moreover, their maintenance is expensive.

Accordingly, we cannot say that all goes well, but this happens unwillingly. What shall we do if there are no other types of progressive machinery? Mechanicians rush to answer the question if there is a need to introduce something new. They say - "What else could you ask for? All machines work. "In fact, according to scientific forecasting, the design of these machines are supposed to be completely different in off-road conditions. Relief irregularities of soil supporting surface affect outrigger wheels with round cover disk strongly. In such cases not only a lot of energy is expended, but all the components and assemblies of undercarriage undergo vibrations, which causes severe wear to occur.

Key words: walking propellers, transportation, vehicle, steppe road-off conditions

\section{INTRODUCTION}

Operation of machines in such conditions shows that supporting pneumatic tires, frames and springs undergo severe wear [1]. Vehicle frames become deformed as a result of complex dynamic force, springs and spring pins are due to change frequently. Engine and transmission units of the machine including undercarriages are also subjected to vibration, and their service lifetime is reduced [2-4].

Earth's surface is a ground for construction workers, and soil for agronomists. The builders want completed construction work on the Earth's surface to be constant, i.e. if the land is packed, then it remains unchanged permanently [5]. Agronomists want soil to be preserved for a long time, having been scarified as the Earth breathes, and needs moisture to create conditions for plant growth. But the Earth has rheological properties, its surface is constantly affected by natural forces from below and above [6]. Consequently, nothing stays constant and unchanged on the Earth's surface.

The construction worker who packed land and covered it with asphalt concrete would still have to repeat the same work after a certain time [7-10]. And the agronomist will have to plow the surface of land under cultivation every year.

All machines processing the soil and harvesting press

*asylkhanasemkhanuly@gmail.com the soil with their pneumatic wheels. If cars drive along the same track for several times, then plants stop growing there. Pneumatic wheel firms surface the land efficiently [11]. In recent years, road builders began to roll asphalt concrete using a roller equipped with pneumatic wheels.

Agronomists urgently require mechanicians to come up with something new and provide tractor transport and self-moving agricultural machinery with other boots that would not firm the soil during agricultural work [12].

Hence, from the sound of things it is time to give life to a walking wheel.

\section{MATERIALS AND METHODS}

Theory/calculation. Figure 1. shows a diagram of a sixlegged Tuk-tuk walking wheel. Such a walking wheel is made integral from one material, shape and dimensions are determined as follows.

Shape of the wheel (Fig. 1a) is performed based on the condition of reducing the number of wheel strikes and frontal obstacles (surface protuberances), i.e. part of the round wheel rim is removed. What part of the rim to be removed depends on road surface topography [13].

In this case, half of rim circumference is removed, i.e. $1 / 6$ part of rim, and 1/6 part is left as the foot of six legs. This is quite enough for the rim not to interfere with frontal obstacles while the wheel moves in a straight line. 


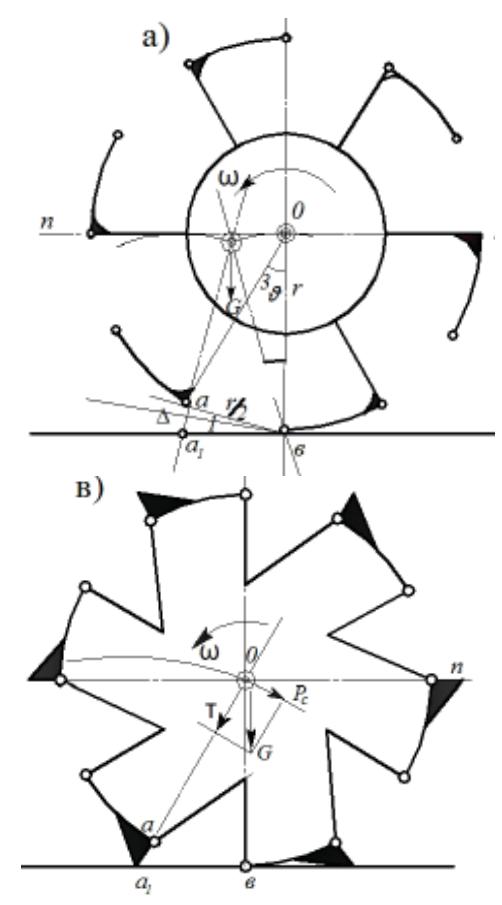

Figure 1: Tuk-tuk walking wheel

Despite the simplicity of the design, Tuk-tuk wheels have a flaw while performing step mode, i.e. when transferring $G$ weight submitted to the center of $O$ hub from one foot to another it falls on the road surface from a height (Fig. 1a) $\mathrm{aa}_{1}$ and at this moment the center of $\mathrm{t} \mathrm{O}_{1}$ hub descends below its straight path and takes a steady stable position of the walking wheel $O_{1} a_{1} B$ which is a statically balanced position [14]. The weight $G$ falling on a single wheel $\mathrm{G}$ is distributed between two bearings $\mathrm{a} 1$ and $\mathrm{B}$ regularly. This position is called steady stable position of the wheel. This position occurs in 1 turn of the wheel for six times. To transfer the wheel from steady stable position in the wheel condition, expenditure on energy is required. One disadvantage of foot falling on the road surface is related to others indirectness of the movement of the hub center and excess energy used to roll the wheel [15].

Accordingly, Tuk-tuk wheels should not be used to drive on an asphalt road, as it may destroy asphalt surface at high speeds.

To correct a defect of Tuk-tuk gait elastic heels are installed on the heel of all legs, working height of which is equal to the length of the height of falling " $\mathrm{aa}_{1}$ ". Calculated "C" stiffness of the heel spring is determined depending on the projection magnitude of the weight $G$ vector. Heel spring keeps center of the hub at the desired height for step mode period, steady stable positions of walking wheel disappear and thus eliminate wheel gait defect, and also raises center of gravity of the machine, which is due to the loss of stability of undercarriages, and decrease in radius reduces wheel flotation while driving on a relief surface (farmland).

With increase in the number of legs, driving comfort rises, but flotation ability diminishes [16].
The height of falling $-\Delta$, depends on the radius of the wheel- $r$, and the number of legs. Wheel radius increases due to increased dead-weight.

For this reason, specified features should be taken into account while designing a walking wheel [17].

For simplicity of construction and reliability of the wheel it is advisable to install hard heels in the conditions of steppe off-road, height of which is equal to height of the heel of the advancing foot $\Delta$. While reaching the bearing surface, the hard heel begins to reduce its height due to its introduction into the soil and thereby ensures directness of the hub center.

For calculation, you can use simple dependencies of wheel parameters. So to determine magnitude of the falling height $\Delta$ of advancing foot of six-legged wheel, you can use dimension ratio of $\Delta \mathrm{aa}_{1} \mathrm{~B}$ :

$$
\begin{aligned}
& \frac{\frac{r}{2}}{\sin \sin 90}=\frac{\frac{\Delta}{2}}{\sin \sin 15^{\circ}} \\
& \text { Or } \Delta=r \cdot \sin \sin 15^{\circ}=r \cdot 0,2588 \\
& \text { If } r=300,
\end{aligned}
$$

Then $\Delta=77,64 \mathrm{~mm}$.

$$
\text { If } r=500 \mathrm{~mm} \text {, }
$$

Then $\Delta=r \cdot \sin \sin 15^{\circ}=500 \cdot 0,2588=129 \mathrm{~mm}$.

Figure 1 в shows one of the variants of a walking wheel made of Nylon "D", equipped with rigid heels. Heels are made with sharp ends and conical body for gradual introduction into the soil ensuring directness of the hub center [18].

Also, heels in the form of a spur loosen the soil while moving which is critical to plant growth.

Six-legged walking wheels are mainly designed for tractors and agricultural machinery. Height of the heels of these wheels is large. Therefore you can drive with such wheels in the fields only.

For vehicles operating in off-road conditions, eightlegged or twelve-legged walking wheels are recommended (Fig. 2).

Calculated height of rigid heel for eight-legged walking wheel is determined as follows:

From $\triangle$ ова1 we have:

$$
o a_{1}=\frac{r}{\sin \sin 78^{0}}=\frac{r}{0,98}
$$

$$
\frac{o a_{1}}{\sin \sin 90^{\circ}}=\frac{r}{\sin \sin 78^{\circ}}
$$

$a_{1} \varepsilon=o a_{1} \cdot \sin \sin 22^{\circ}=0,38 \cdot r$

$$
\frac{a_{1} \varepsilon}{\sin \sin 22^{\circ}}=\frac{o a_{1}}{\sin \sin 90^{\circ}}
$$

$\sin \sin 22^{\circ} \quad \sin \sin 90^{\circ}$
from $\Delta$ aa1 8 we have: $\Delta=a_{1} \varepsilon \cdot\left(\frac{11^{0}}{180^{\circ}} \cdot \pi\right)=0,072 \cdot r$ 
a)

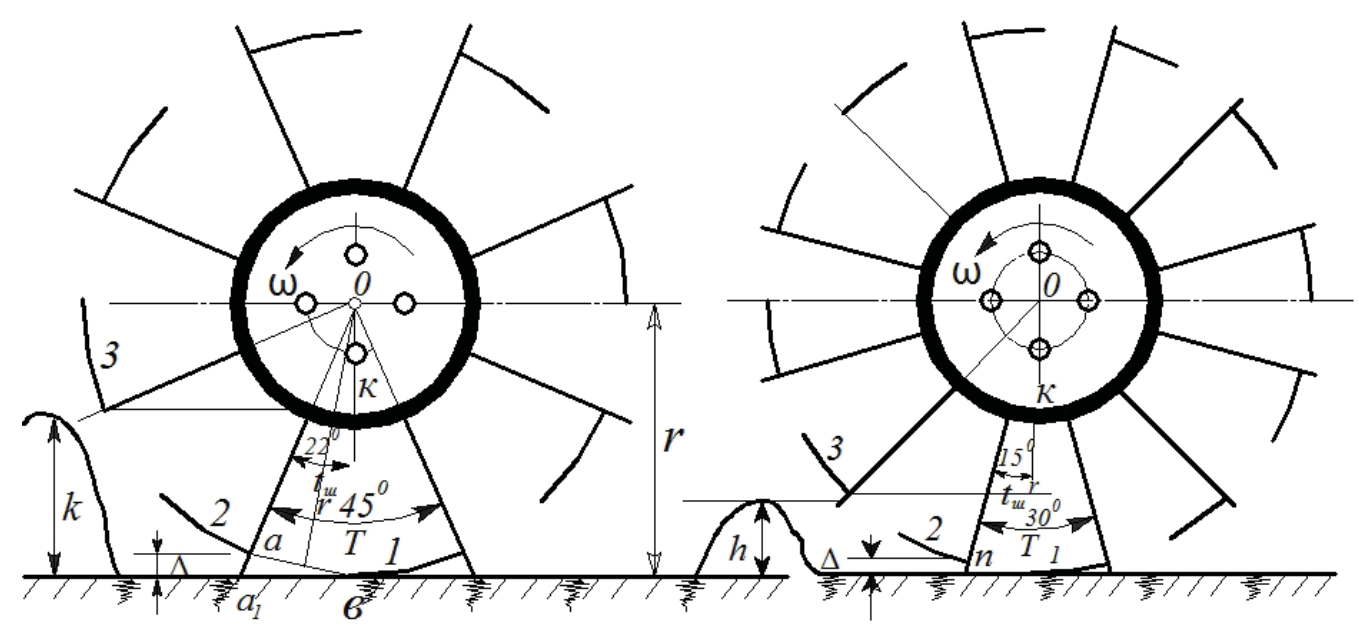

B)

Figure 2: Diagram of eight and twelve-legged walking wheels
If accepted wheel radius is $r=350 \mathrm{~mm}$, then:

$\Delta=0,072 \cdot r=25 \mathrm{~mm}$.

If wheel length is accepted

$\mathrm{r}=500 \mathrm{~mm}$, то: $\Delta=0,072 \cdot r=36 \mathrm{~mm}$

If $r=300 \mathrm{~mm}$, то: $\Delta=0,072 \cdot r=22 \mathrm{~mm}$.

Radius of the walking wheel is taken according to the conditions of pushing the foot of the third leg of the wheel as the first and second feet are on the supporting surface [19].

Height $\mathrm{h}$ protruding above the supporting surface is the average height of the obstacle. This height is set for a large area of the territory where the vehicle operates frequently. Length of the radius $r$ is set according to the conditions of:

$$
h=r-r \cos \cos \beta ; \quad h \leq[h] .
$$

where $h$ is the height of the obstacle, and [h] is the allowable height value

$r$ is radius of the wheel

$\beta$ - angle of the third leg to the vertical axis of the wheel.

For eight-legged walking wheel

angle $\beta=[67]^{\wedge} 0$ (see fig.2a), since full step $T=450$, and step angle $t_{s}=220$ (since half of the angle $T$ ).

then from:

$h=r(1-\cos \cos \beta)=[h]$,

we obtain: $r=\frac{[h]}{1-\cos \cos \beta}$;

or: $r=1,64[h] \mathrm{mm}$.

This means, if the average allowable value of the obstacle height is $300 \mathrm{~mm}$, i.e. [h] $=300 \mathrm{~mm}$

then: $r=1,64 \cdot 300=492 \mathrm{~mm}$.

A wheel with a diameter of $\mathrm{dk}=984 \mathrm{~mm}$ can even drive through quite broken terrain easily without crashing with obstacles.
Amenities of driving vehicles with twelve-legged walking wheels increase significantly. Height of advancing foot is reduced; consequently, height of the heel is not high:

$a_{1} \varepsilon=\frac{r}{4}$;

Consequently $\Delta=\frac{r}{4}\left(\frac{7,5^{0}}{180^{0}} \cdot \pi\right)=0,03 \cdot r$;

If $\mathrm{r}=300 \mathrm{~mm}$, to: $\Delta=0,03 \mathrm{r}=0,03 \cdot 300=9 \mathrm{~mm}$

If $\mathrm{r}=400 \mathrm{~mm}$, then: $\Delta=400 \cdot 0,03=12 \mathrm{~mm}$

If terrain relief is characterized by $[\mathrm{h}]=300 \mathrm{~mm}$, then

$r=\frac{[h]}{1-\cos \cos \beta} ;$

Where: angle $\beta=30^{\circ}+15^{\circ}=45^{\circ}$ consequently

$r=\frac{300}{1-0,7}=1000 \mathrm{~mm}$.

The wheel is obtained with a diameter of more.

On off- road with $[\mathrm{h}]=150 \mathrm{~mm}$ :

$r=\frac{[h]}{1-\cos \cos \beta}=\frac{150}{0,3}=500 \mathrm{~mm}$.

In the mid-broken terrain [h] $=150 \mathrm{~mm}$, you can drive comfortably at high speeds on cars with twelve-legged walking wheels with a diameter of $1 \mathrm{~m}$ and a rubber heel in height: $\Delta=500 \cdot 0,03=15 \mathrm{~mm}$.

Thus, in off-road conditions in the steppe regions of Kazakhstan, you can successfully drive vehicles with eightlegged or twelve- legged walking wheels [20].

At the same time, movement energy expenditure is reduced by half compared to pneumatic wheels, and average speed of vehicles increases and fuel savings will be at least $30 \%$. For all that, wear of the running gears of the car is reduced, if truck undercarriages are performed to be self-aligning and the principle of car turn is changed.

Relief off-road surface, disorderly located humps and 
holes also have an amorphic effect on the frame of the car through wheels while driving vehicles [21]. Rigid frame and machine suspension are experiencing complex deformation. Depending on running speed, the stress state of the parts increases, driving comfort and dynamic stability decrease. Under such conditions, if the mobility number of the undercarriage mechanism is excessive, then inertial factors control these excess degrees of mobility and the machine loses controllability.

Therefore, while designing the undercarriage mechanism, the degree of mechanism motion relative to the supporting surface should be tested.

If the number of degrees of mechanism motion is equal to two (no more and no less), then there is a guarantee of dynamic stability of the car driving at high speeds in offroad conditions. Upon that accuracy of steering mechanism is also of great importance.

Thereupon anatomical (structural) scheme of undercarriage mechanism designed for off-road driving should be tested at design stage [22].

Fig. 3. demonstrates a constructive scheme of undercarriage of vehicles without excessive degrees of mobility, which consists of drive front axle housing 1 , which is rigidly bound with common frame 2 .

Inside housing there are left and right tube drive shafts 3 one ends of which are made in the shape of the drum where the ratchet pawl 4 of the ratchet is mounted 5, the other ends of leading tube drive shafts are connected with splines to the driving disk 7 of final drive from through -going shaft 8 at the ends of which jointed walking wheels 6 are mounted.
Leading walking wheels 6 and tube drive shafts (right and left) 3 are interconnected by means of pallets 4 and ratchet plate 5 of ratchet clutch. As a result, drive shafts 3 and leading walking wheels 6 form a rigid system (like a pair of wheels) as drive shaft rotates in one direction, and neither leading wheels 6 nor through -going shaft 8 rotates as drive shaft rotates in the other direction,i.e. there is no reverse travel.

To rotate undercarriage using steering mechanism (not shown in the Diagram) rear steering wheels 9 are rotated relative to rotary joint " $\mathrm{K}$ " of vertical axis 10 of rear axle 11.

To unload external effects of road surface irregularities undercarriage frame is ganged, i.e. consists of two parts - common frame 2 and half-frame of rear axle 11. These frames are interconnected by means of rotary joint "e" which allows half-frame 11 to rotate relative to common frame 2 around the longitudinal axis of undercarriage. Moreover, this rotary joint has limited mobility and is provided with shock absorbing.

With parallel four walking wheels undercarriage moves rectilinearly ahead. If under rectilinearly movement the rear axle is rotated relative to the vertical axis of rotary joint " $K$ " then frame 2 rotates. In this case, one of the ratchet couplings releases the walking wheel from connection with drive shaft and wheel stops.

At this time, another walking wheel is moving and undercarriage rotates relative to the instantaneous center of IC [23].

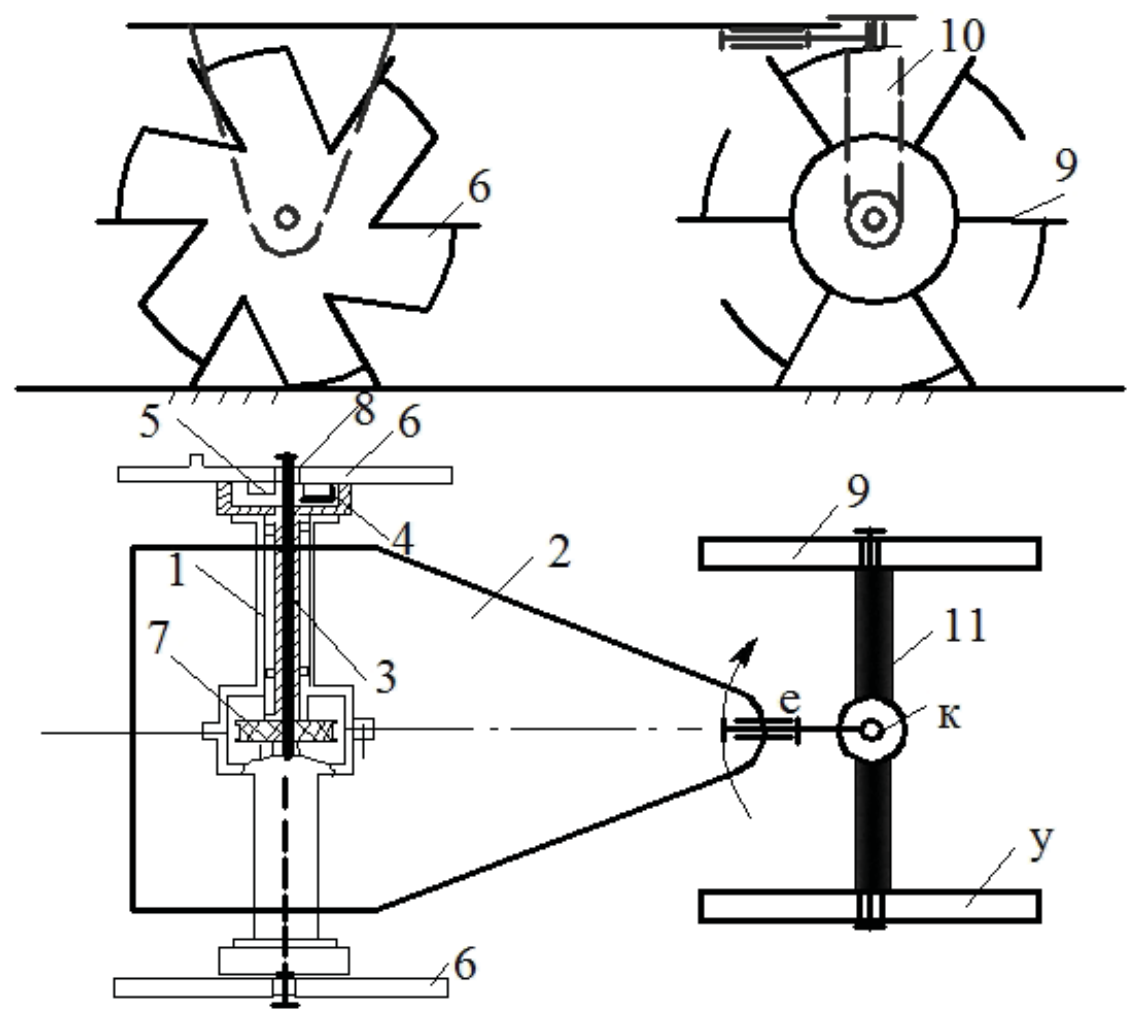

Figure 3: Undercarriage Mechanism Diagram 
Fig. 4. shows undercarriage simplified block diagram under rectilinearly movement. Number of independent elements (links) is five (this is a common frame 1 , wheelset 6 , rear axle half-frame 11, two walking steered wheels 5 and 6$)$, that is: $n=5$.

Number of one-mobile rotary joints is five (these are $\mathrm{f}, \mathrm{e}$, k, B, z), i.e.: $P 1=5$.

Due to the presence of unloading rotary joint "e" undercarriage always stands on four supports.

Three contacts of four walking wheels with supporting surface form kinematic pair with five mobility, i.e .: $P 5=3$.

Then, amount of total mobility of undercarriage relative to supporting surface is equal to:

$W=6 \cdot n-5 \cdot p_{1}-p_{5}=6 \cdot 5-5 \cdot 5-3=2$

Undercarriage is uniquely controlled by two drives, i.e. it is controlled by engine and driver with the help of steering wheel; it has no excess mobility and redundant connections.

Figure 4. shows the block scheme of undercarriage when rotated [24].

If rear axle 4 with two walking wheels 5 and 6 is rotated about axis of vertical pillar 10 (Fig. 3), i.e. relative to rotary joint "K" in clockwise direction, left ratchet coupling releases left walking wheel from coupling with driving tube shaft and it reduces number of rotations in comparison with right walking wheel up to stop. It depends on the position of the instantaneous center of IC. The structure of the undercarriage mechanism is changed.

Number of independent elements (links) becomes equal to six (walking wheels 3 and 2, common frame 1 , rear axle 4 and rear walking wheels 5 and 6 ), i.e. $n=6$.

Number of single-motion rotary joints becomes six (this is $d, f, e, k, b, z$ ), i.e $P 1=6$.

The number of support kinematic pairs of four walking wheels, i.e. kinematic pairs with five mobilities become four, i.e. $P 5=4$.

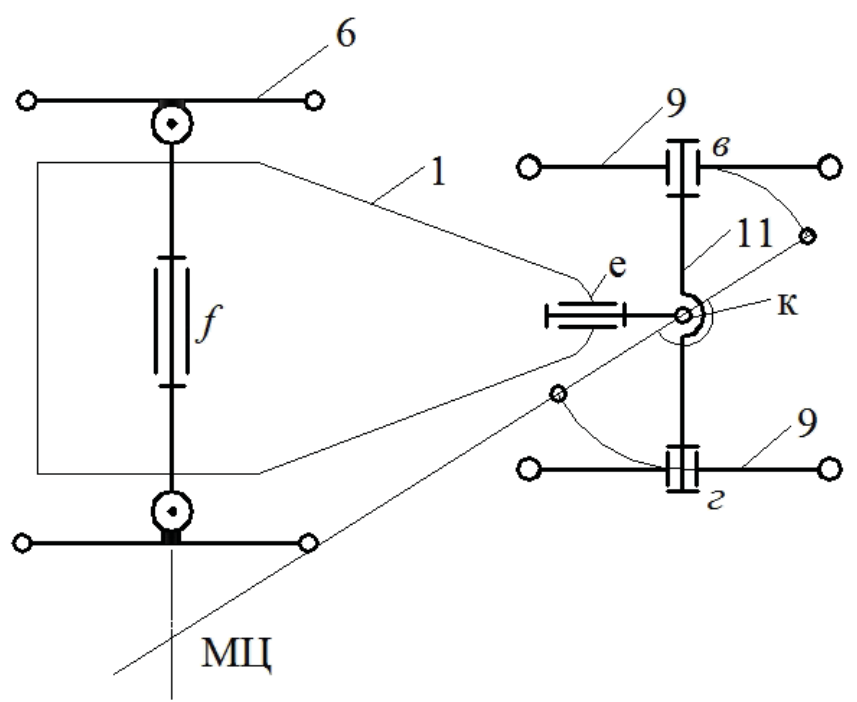

Figure 4: Block scheme of undercarriage mechanism

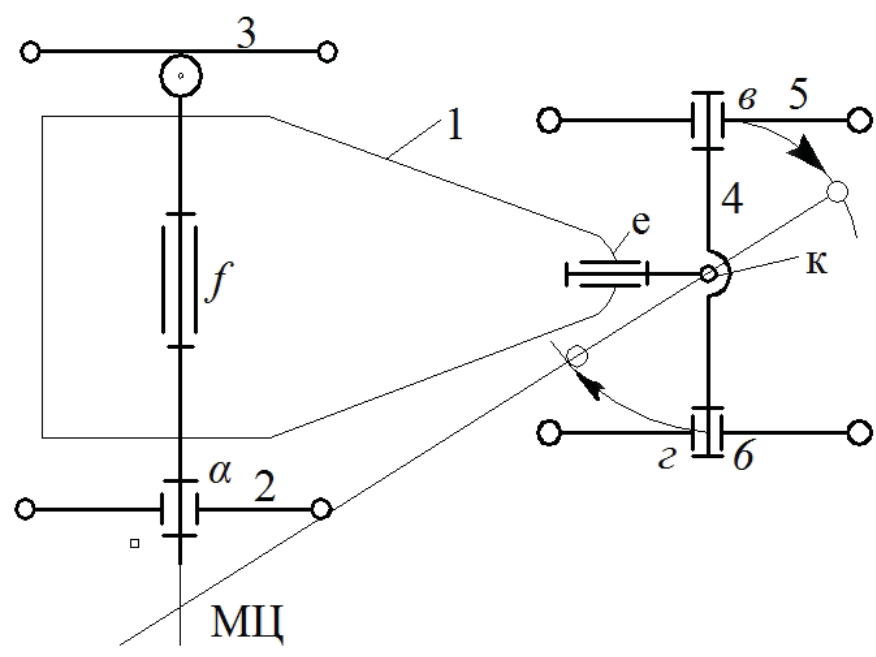

Figure 5: Undercarriage structural scheme when rotated In comparison with the first case, the number of five-mobile pairs has increased. This is due to the fact that when the rotated wheelset is missing.

As a result, total mobility of undercarriage under rotating is equal to:

$W=6 \cdot n-5 p_{1}-p_{3}=6 \cdot 6-5 \cdot 6-4=2$.

This shows that the anatomical structure of the undercarriage mechanism does not change when rotating.

\section{RESULTS AND DISCUSSION}

Thus, it may be affirmed that the proposed undercarriage mechanism for vehicles has rational self-aligning structure that is resistant to various kinds of impact arising from supporting surfaces.

Figure 6 . shows a picture of the current model which demonstrates operation of mechanisms of the front axle changing the structure during rotation and rectilinear movement of undercarriage. The operation of undercarriage mechanism precise rotation has also been tested.

To drive vehicles not only off-road, but also on asphalt roads in cities, it is necessary to create a walking wheel design that is not inclined to damage the surface of as-

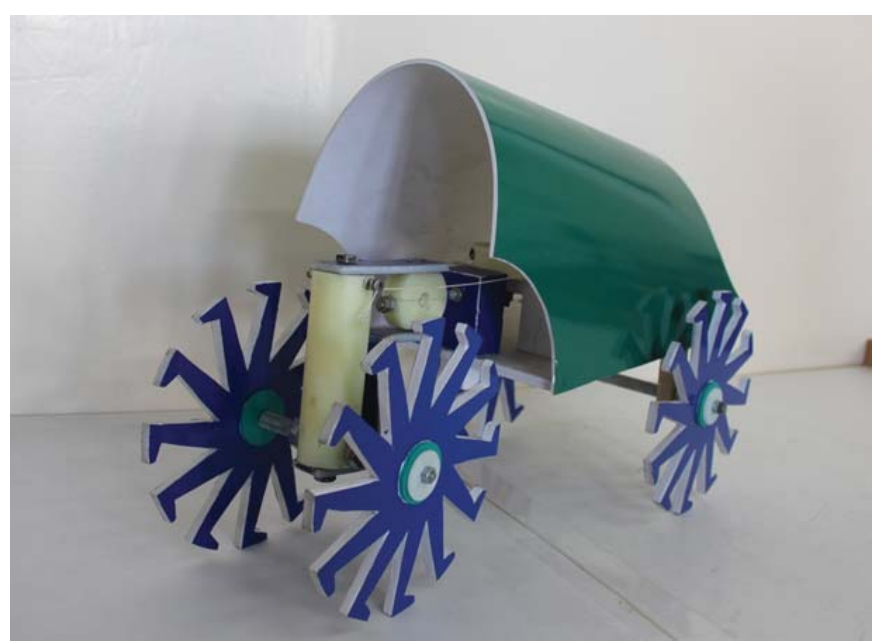

Figure 6: Model of cars 
phalt concrete and does not pollute the air basin of large cities. Walking wheels are the simplest designs, i.e. Integral wheel designs can damage the road surface as the process of falling on advancing foot at high speeds is inevitable.

Observing the gait of birds, and a man, we see that one can walk without falling from one foot to another. Even four-legged animals, for example, pacing horses walk comfortably without sharp falls while some of their other relatives walk so ugly that riders get tired of riding.

Four-legged predators approach their prey to be imperceptible standing on three legs, rearrange the fourth leg, and only then transfer the center of gravity of their body to the next three legs. To study the process of a man's quiet gait carefully, let us observe our gait. For an inconspicuous gait rearranging one leg, we do not transfer the center of gravity of the body onto it, but leave it on the standing leg. Then, we try to extend the rearranged leg, and gently let it down to the ground. Then, we transfer the center of gravity of our body to the foot we made a step with. In this case, impact of landing of the foot on the supporting surface is excluded. This process is easily carried out by walking wheel design.

For this, the walking wheel must be composed of two elements joined together with a rotary joint, so-called knee joint. Figure 7. shows this construction.

First, we build a wheel with a round rim with a radius of r. Then divide the circumference of the rim into 12 equal parts $1-2,2-3,3-4, \ldots 12-1$. Six parts of the rim are removed, i.e. we remove parts 1-2, 3-4, 5-6, 7-8, 9-10, 1112. We get a wheel, consisting of six legs (radius) - $0-10$, $0-12,0-2,0-4,0-6,0-8$; with feet (rims in the form of an arc of radius $r$ ) -10-11, 12-1, 2-3, 4-5, 6-7, 8-9. There will result in a six- legged single-part walking wheel standing on the tip "в" of the first leg - 0-10-11, and at this time the second leg 0-12-1 begins to fall on the heel "a" from height a-a1.

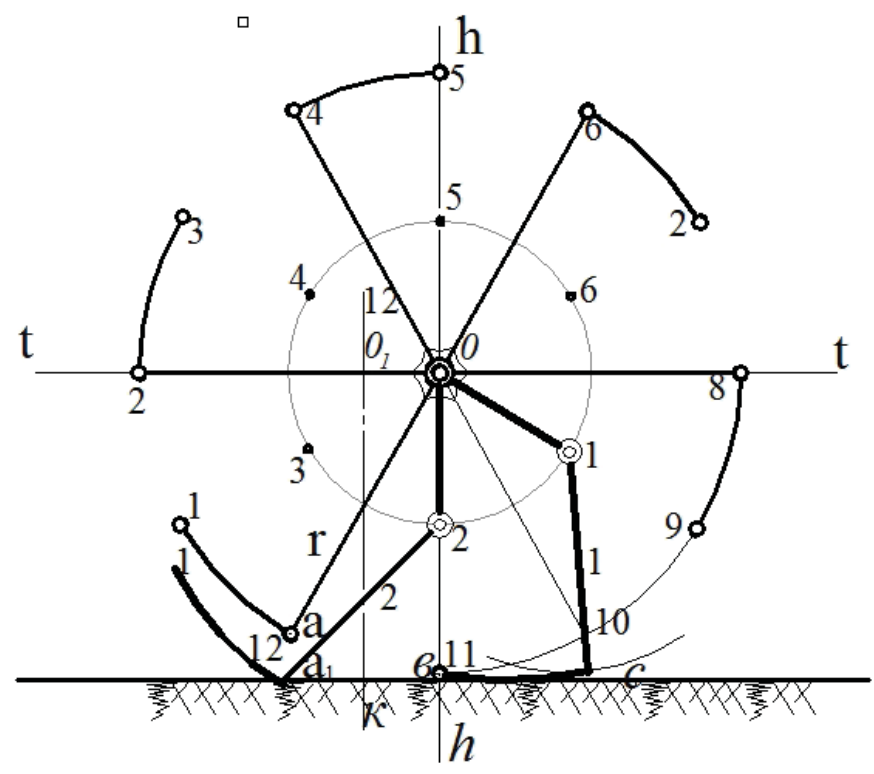

Figure 7: Design scheme

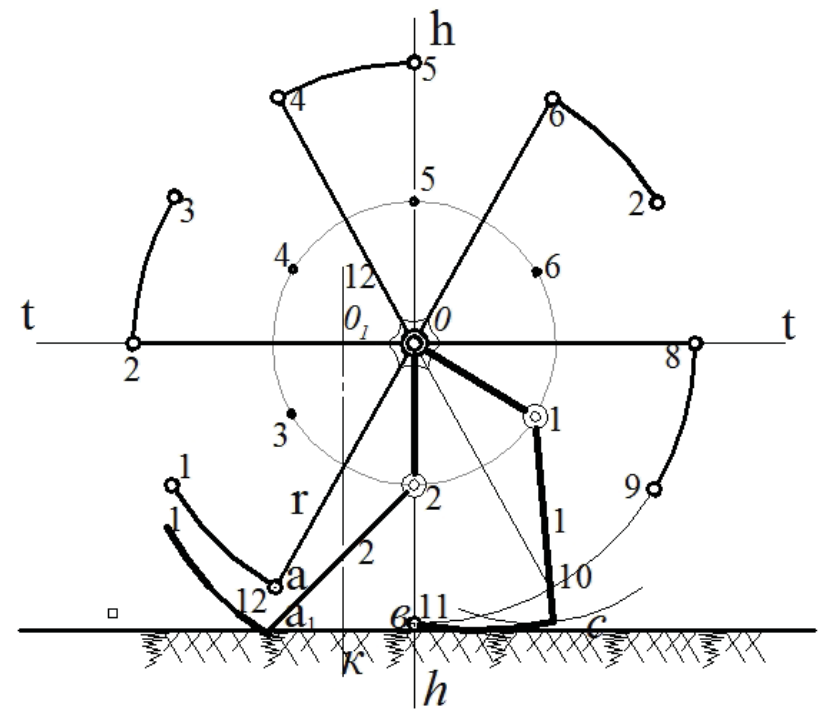

Figure 8: Designing the circuit at the end of single-step mode

In order to eliminate this fall, radius " $0 \mathrm{a}$ " is replaced by two elements: a12 (shank) and 02 (hip). Moreover, shank "a12" is rigidly made with sole (foot) - 1-a1; the length of the shank "a12" is meant to be that knee joint 2 coincides with the vertical axis of the wheel $-\mathrm{hh}$. Then the first 1-C-11 will occupy $0-1-\mathrm{C}-11$ position, as shown in Figure 25 (in bold lines). In this position, the walking wheel holds weight $G$ falling on a single wheel with foot $\mathrm{C}-11$ of the first leg, and the second leg takes only a supporting position at the point a1. Further displacement of hub center 0 to the position 01 in a straight line tt leads to gradual loading of only advancing leg - 0-2-a11.

Then the center of the wheel hub occupies position 01 as shown in Figure 8. Thin lines show positions of mechanism scheme of two-supporting legs while hub center occupied position at point 01 . The hub center does not deviate from rectilinear trajectory tt because an elastic element (shock absorber) is installed in knee joint rigidity of which is designed to change the load (weight) G.

Although hub center point $\mathrm{O} 1$ occupies position corresponding to the equilibrium position of the schemes of the mechanisms of the legs $012^{1} \mathrm{a}$ and $011^{1} \mathrm{C} 1 \mathrm{~B}$ when the weight $G$ is evenly distributed between two reference points $\mathrm{a}$ and $\mathrm{B}$ (normal response at points $\mathrm{a}$ and $\mathrm{B}$ ), the stable position of the wheel will not come, and additional expenditure of energy for further movement of wheel hub center $\mathrm{O} 1$ is not required. Further movement of hub center under effect of driving force of drive arising from position $\mathrm{O} 1$ to position $\mathrm{O} 1$ is shown in Figure 9. As it is clearly seen as wheel hub $\mathrm{O} 2$ reaches the center of the wheel, the first leg of walking wheel already detaches from supporting point " $c$ " and weight $G$ fully loads the second leg of the wheel $(G=N)$.

Because of cross coupling of weight $G$ and stiffness of elastic element of knee joint "C" angular deformation of the elastic element from $\alpha 1$ to $\alpha 2$ occurs, which determines displacement of hub center point along rectilinear trajectory $\mathrm{tt}$. 


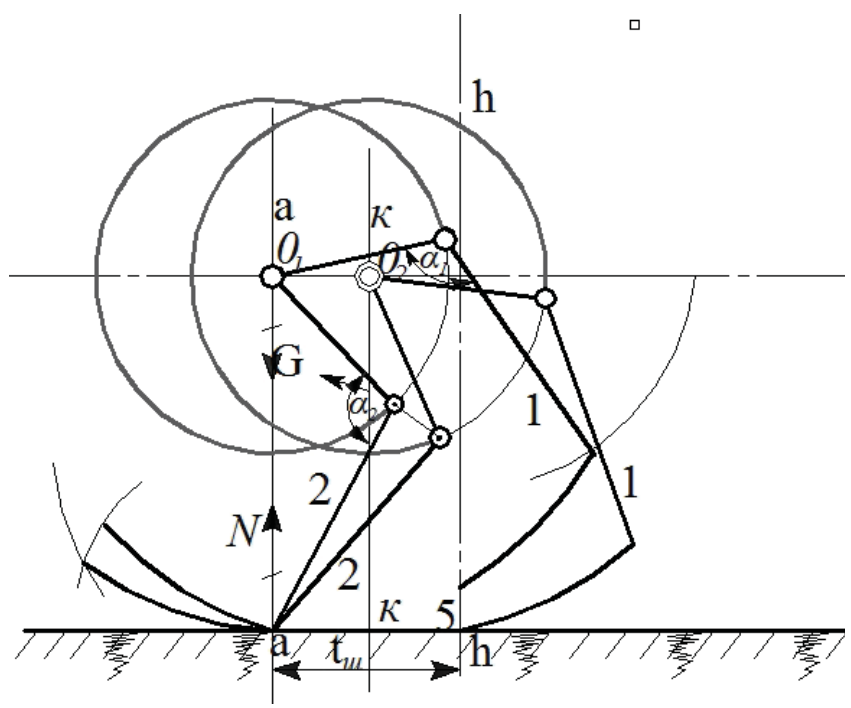

Figure 9: Designing the circuit at the end of single-step mode

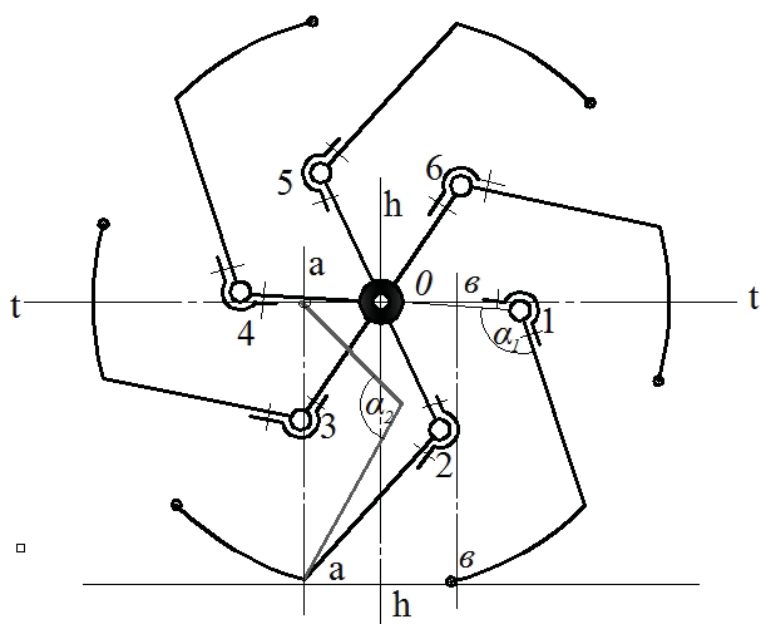

Figure 10: Diagram of universal walking wheel

Resulting design scheme of the walking wheel is shown in Figure 10. This design of walking wheel with elastic legs is of the type "Kanbak (which means "rudderless") ".

Softness of this wheel motion is achieved by moving the wheel hub center standing on two supports in the process of performing stepping mode. This property of the wheel softens motion, as well as increases dynamic stability of the wheel counteracting effects of irregularities of supporting surface. With all this, the wheel does not lose a degree of flotation to frontal obstacles. Considering the above mentioned advantages of this wheel let's call it a universal walking wheel, since it can comfortably drive on flat surfaces of the road, as well as off-road. This wheel seems to replace common pneumatic wheels of vehicles over time. Simplicity of the design, reliability and environmental friendliness of universal walking wheels will have to get general recognition of designers and we hope that the best design performance will appear soon.

Any car enthusiast and professional would appreciate it if their iron horse would be equally comfortable driving an asphalt road and off-road.

Figure 11. shows a picture of the current layout of the

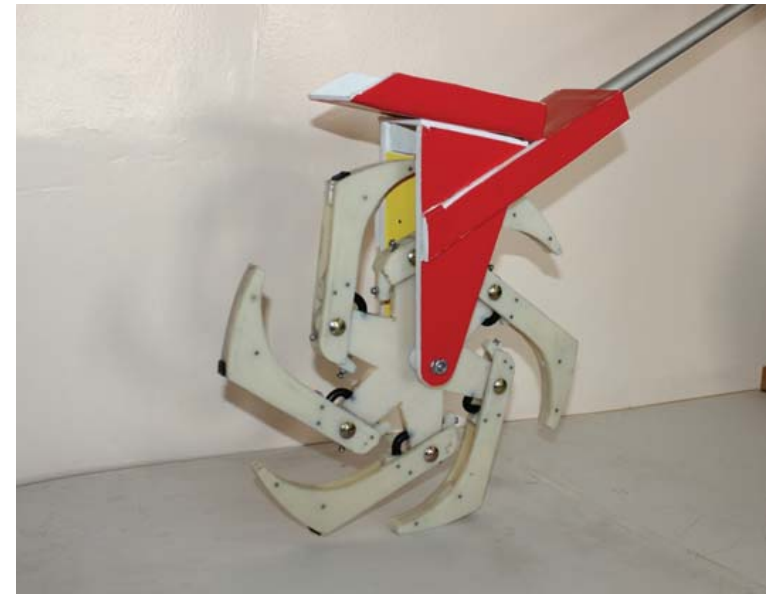

Figure 11: Picture of universal walking wheel model

universal walking wheel, which was made to test certain properties of new wheel.

In the future it remains to work out design, for instance, to select materials of the hub and ankle successfully, as well as to calculate elastic elements properly.

To work on longitudinal slopes of the mountains it is not enough to fit only the wheel, there is still a need to fit a vehicle frame.

Primary rigid frame of vehicles can be designed as a composite structure called an adaptive frame that always retains its vertical position regardless of inclination of supporting surface with supporting wheels and ganged frame. Thereby longitudinal stability is contained.

A ganged frame consists of two side half-frames, one on each pair of right and left walking wheels, which are installed on four transverse frames, two of them connected to side frames hingedly forming end parallelogram mechanisms.

In the middle of transverse end half-frames there are two holes for installing the driver's cabin with the engine, where the main weight of the self-moving undercarriage is concentrated to control the position of the undercarriage mechanism.

Parallelographic mechanisms are controlled by undercarriage weight. Since weight force is always directed vertically regardless of vehicle position on the supporting surface it always maintains vertical position of side frames and wheels.

Figure 12 shows positions of frame and wheels in thin lines when the vehicle is traveling on an inclined plane.

Figure 13. shows a structural diagram of vehicle undercarriage consisting of right and left half-frames with pairs of walking wheels mounted on them, four end frames half-ganged with side frames forming two identical parallelogram mechanisms.

In the middle part of these parallelogram mechanisms the driver's cabin is hinged without disturbing symmetry of end parallelogram mechanisms.

While driving on a longitudinally inclined surface vehicle adapts as shown in Figure 14. 
a)
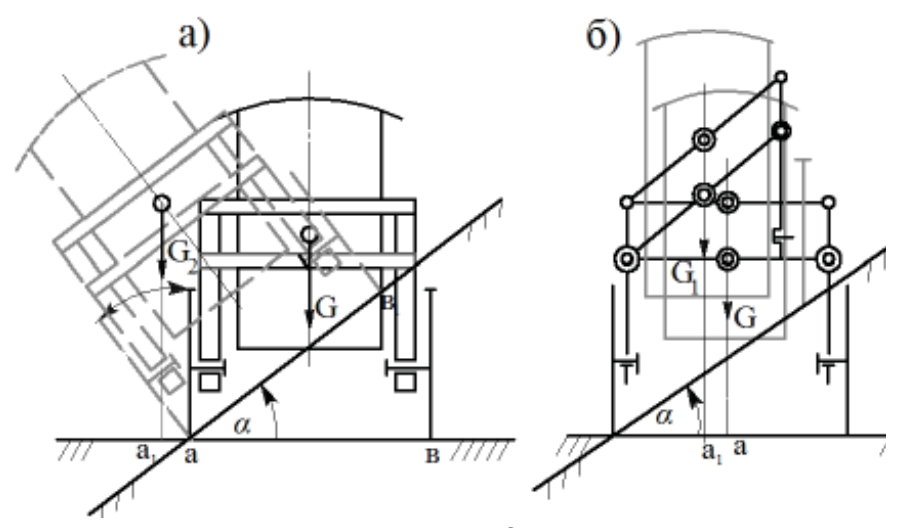

Figure 12: Kinematic frame diagram

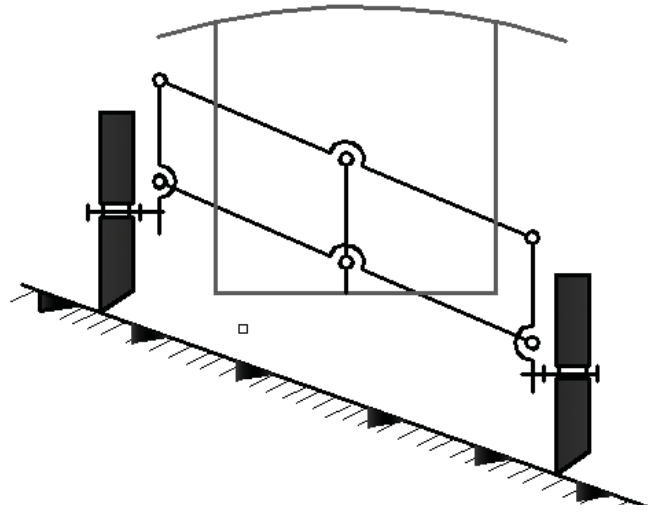

Figure 13: Scheme of vehicle undercarriage on horizontal supporting surface

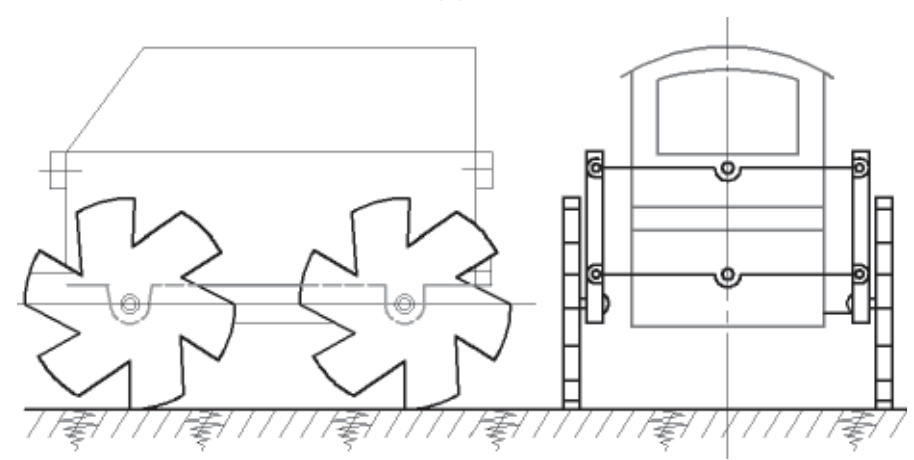

Figure 14: Scheme of vehicle undercarriage on inclined supporting surface

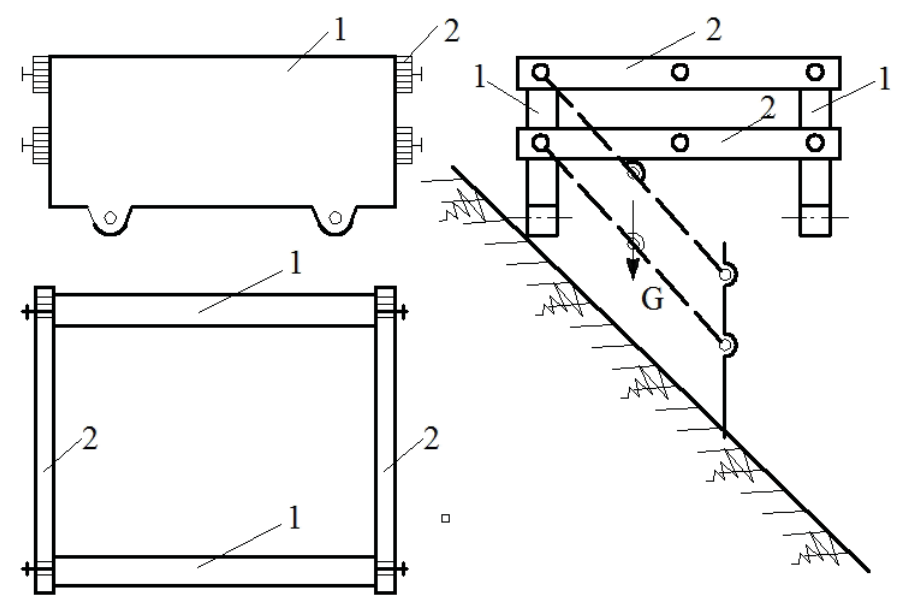

Figure 15: Design model
Figure 15 demonstrates how stability of a vehicle changes while driving along a longitudinally inclined surface, when its frame is single-part (Fig. 15a) and when the frame of the vehicle is adaptive (Fig. 15 b.).

\section{CONCLUSION}

In conclusion, we can state that today general constructive design of elevated transport, specifically passenger cars, both in our country and abroad, differs little from their initial production. Adjustments in the exterior shape and interior communication as a product for business do not affect the fundamental change in design.

Average weight of a vehicle surpasses three or more times the total weight of four people whereas to solve an environmental problem it would be more effective to make the weight of the vehicle be equal to the weight of four people.

In fact, in recent years, flotation of wheeled vehicles has increased significantly and in many cases it is closer to a track-type machine. However, the closer wheeled vehicles and track-type machines are in flotation, the smaller the difference is in efficiency of their propelling devices. In equal conditions of loads and roads losses in both types of propelling devices differ little.

As it was noted, the unsuccessful anatomical structure of undercarriage of modern passenger cars and loaded transmission mechanisms increases the weight of the car. Consequently, it is required to find a new undercarriage scheme enabling to abandon heavy, low-efficiency transmission mechanisms and principle of undercarriage rotation using differential with rear axle drive.

In this regard, we would like to address designers of automobile plants and businessmen with a proposal to start production using the design of two-point, threepoint and four-point propellers of universal motion. When conditions are provided for maintenance of vertical position of traveling wheels, design of the vehicle becomes similar to the anatomy of the musculo-skeletal system of rocky-mountain goats that preserve vertical stability of the body on cliffs without fail.

\section{REFERENCES}

1. Walker, M. A., Brown, D. B., Manifee, D. R., \& Puckett, C. D. (2019). U.S. Patent No. 10,169,929. Washington, DC: U.S. Patent and Trademark Office.

2. Wang, H., Huang, Y., Khajepour, A., He, H., \& Cao, D. (2017). A novel energy management for hybrid off-road vehicles without future driving cycles as a priori. Energy, 133, 929-940.

3. Guskov, V., Mikulic, T., Pavlova, V., \& Sochnev, A. (2018). The theoretical basis of the method of optimizing parameters of the propulsion multipurpose wheeled vehicles. In MATEC Web of Conferences (Vol. 182, p. 01031). EDP Sciences. 
4. A.Kainarbekov, A.Omarov, A.Muratov A. Hikayat of a walking wheel. "LAP" LAMBERT Academic Publishing, Saarbrucken, Germany, 2014.

5. Tsvetkov, V. V., \& Rusopov, V. L. (2019, October). Development of vehicles to be operated on rough roads and in off-road conditions. In IOP Conference Series: Materials Science and Engineering (Vol. 632, No. 1, p. 012009). IOP Publishing.

6. Nagarkar, M. P., Patil, G. J. V., \& Patil, R. N. Z. (2016). Optimization of nonlinear quarter car suspension-seat-driver model. Journal of advanced research, 7(6), 991-1007.

7. Muratov A., Omarov A., Kainarbekov A., Sazanbaeva R. Walking wheels. - Almaty. 2014

8. Lin, Q., Xu, X., Zou, T., \& Yang, J. (2018, December). Design and Simulation of an Extended-Range Dynamic System for an Amphibious Vehicle. In IOP Conference Series: Materials Science and Engineering (Vol. 452, No. 4, p. 042153). IOP Publishing.

9. Serdobintsev, Y. P., Ivanyuk, A. K., \& Karlov, V. I. (2019, March). Experimental Determination of the Passability Characteristics of Mobile Robotic Complex with Adaptive Wheels. In 2019 International Conference on Industrial Engineering, Applications and Manufacturing (ICIEAM) (pp. 1-6). IEEE.

10. Bekenov, T. N., Nussupbek, Z. T., \& Tassybekov, Z. T. (2017). DEVELOPMENT OF MODEL OF WHEEL SLIPPAGE SELF-PROPELLED VEHICLES ON BENDS. Trans Motauto World, 2(3), 102-103.

11. Muratov A., Serikkulova A., Nikitin E. Vertical stability of vehicle chassis with adaptation mechanism with parallelogram effect. The Journal of Industrial Transport of Kazakhstan 2017 №1 (54), pp. 62-66. Almaty city.

12. Muratov A., Omarov A., Kainarbekov A., Bekmambet K. Vehicles for driving on extremely difficult surfaces. (Construction and calculations). - Almaty, 2016.$117 p$.

13. Zhileykin, M., Zakharov, A., \& Panshin, M. (2019, August). Mathematical model of interaction of a rolling elastic wheel with elastic-visco-plastic support base taking into account the history of loading. In IOP Conference Series: Materials Science and Engineering (Vol. 589, No. 1, p. 012027). IOP Publishing.

14. Petrescu, R. V., Aversa, R., Akash, B., Abu-Lebdeh, T., Apicella, A., \& Petrescu, F. I. (2018). Some aspects of the structure of planar mechanisms. American Journal of Engineering and Applied Sciences, 11(1), 245-259.

15. Muratov A., Serikkulova A.T., Nikitin E., Asemkhanuly A. Synthesis of the mechanism scheme of vehicles adaptive frame during the universal course I Magazine "Industrial Transport of Kazakhstan", 2017, №4 (57), p.103-106, Almaty city.
16. Muratov A., Kainarbekov A., Serikkulova A.T., Asemkhanuly A. Interdependencies of geometric parameters and anatomical structure of adaptive-elastic suspension for four-support vehicles / Magazine "Industrial Transport of Kazakhstan”, 2018, №1 (58), p. .74-79, Almaty.

17. Muratov A.M., Asemkhanuly A., Niyazova Zh. Synthesis of Walking musculoskeletal mechanisms / Materials of XIV International scientific and practical conference "CONDUCT OF MODERN SCIENCE - 2018" November 30- December 7, 2018, Volume 15 , Geography and geology, Mathematics, Technical science, Chemistry and chemical technology s. 7276, Sheffield, Science and education Itd 2017

18. A.Muratov., A, Kainarbekov, Assemkhanylu A. Determining the number of vehicles / Journal "Industrial Transport of Kazakhstan”, 2018, No. 3 (60), pp.142146, Almaty.

19. Muratov A., Bekmambet K., Asemkhanuly A., Niyazova $\mathrm{Zh}$. Features of the installation of the adaptive suspension mechanism relative to the direction of movement, depending on the design of the ovehicles' wheels / Journal "Industrial Transport of Kazakhstan", 2019, №1 (62), p.52-56, Almaty.

20. Kaynarbekov A., Omarov A.D., Muratov A., Bekmambet K. Off-Road Vehicles / Almaty, 2015 - 182p. "Alla Prima" LLP.

21. Kainarbekov A., Muratov A. Research of the musculoskeletal apparatus interaction of vehicles with the supporting surface / Electronic journal "Mining Science and Technology", Moscow. (http://mst.misis.ru/ jour/index)

22. Omarov, B., Altayeva, A., Turganbayeva, A., Abdulkarimova, G., Gusmanova, F., Sarbasova, A., ... \& Omarov, N. (2018, November). Agent based modeling of smart grids in smart cities. In International Conference on Electronic Governance and Open Society: Challenges in Eurasia (pp. 3-13). Springer, Cham.

23. Wang, Y., Jiang, B., Wu, Z. G., Xie, S., \& Peng, Y. (2020). Adaptive Sliding Mode Fault-Tolerant Fuzzy Tracking Control With Application to Unmanned Marine Vehicles. IEEE Transactions on Systems, Man, and Cybernetics: Systems.

24. Houle, S. X., \& Hunt, J. M. (2018). U.S. Patent Application No. 15/986,226.

Paper submitted: 16.05.2020.

Paper accepted: 30.07.2020.

This is an open access article distributed under the CC BY 4.0 terms and conditions. 